\title{
Colonização micorrízica arbuscular e tolerância ao mal-do-Panamá em mudas de banana-maçã ${ }^{1}$
}

\author{
Colonisation of arbuscular mycorrhiza and tolerance to Panama disease in seedlings \\ of the maçã banana
}

\author{
Deusiane Batista Sampaio ${ }^{2 *}$, Paulo Furtado Mendes Filho ${ }^{3}$, Aldênia Mendes Mascena ${ }^{4}$, Vânia Felipe Freire \\ Gomes $^{3}$ e Francisco Valderez Augusto Guimarães ${ }^{5}$
}

\begin{abstract}
RESUMO - O objetivo desse trabalho foi avaliar o efeito da colonização micorrízica arbuscular na tolerância da bananeira, cv. Maçã, ao mal-do-Panamá, sob diferentes fontes de nutrientes. Utilizou-se um delineamento inteiramente casualizado com fatorial 2 x 4 [ 2 densidades de esporos de FMA nativos (D1 - 3.500 esporos kg-1 solo e D2 - 7.000 esporos kg-1 solo) e 4 diferentes concentrações de fontes de nutrientes - três de solução nutritiva (SN 40\%, SN 70\% e SN 100\%) e uma de biofertilizante $100 \%$ (B4)] com três repetições. Após o plantio inoculou-se Fusarium oxysporum f.sp. cubense e posteriormente avaliou-se matéria seca da parte aérea (MSPA), o teor de fósforo foliar (P), a colonização micorrízica, o pH do solo e o índice de severidade da doença (ID). As diferentes fontes de nutrientes influenciaram a matéria seca da parte aérea, o teor de fósforo, a colonização micorrízica e o índice de severidade da doença, porém não influenciaram o pH da solução do solo. O biofertilizante não atendeu à demanda nutricional das plantas, as quais se mostraram pouco desenvolvidas. Porém proporcionou intensa colonização micorrízica e menor índice de severidade da fusariose, o qual aumentou com a adubação mineral.
\end{abstract}

Palavras-chave: Banana. Micorriza. Biofertilizantes.

\begin{abstract}
The aim of this study was to evaluate the effect of the colonization of arbuscular mycorrhiza on the tolerance to Panama disease of the banana plant cv. maçã under different sources of nutrients. A completely randomized design was employed, having a 2 x 4 factorial [2 densities of native FMA spores (D1 - 3,500 spores kg-1 soil and D2 - 7000 spores kg-1 soil) and four different concentrations of nutrient sources - three of a nutrient solution (SN 40\%, SN 70\% and SN 100\%) and a 100\% solution of bio-fertiliser (B4)], with three replications. After planting, the seedlings were inoculated with Fusarium oxysporum f.sp. cubense, and later the shoot dry matter, leaf phosphorus content, mycorrhizal colonization, soil $\mathrm{pH}$ and disease severity index were evaluated. The different nutrient sources affected the shoot dry matter, the phosphorus content, the mycorrhizal colonization and the disease severity index, but did not affect the $\mathrm{pH}$ of the soil-solution. The bio-fertiliser did not meet the nutritional demands of the plants, which remained underdeveloped, however it promoted intense mycorrhizal colonization and lower manifestations of fusarium. The latter increased under mineral fertilization.
\end{abstract}

Key words: Banana. Mycorrhiza. Biofertilizer.

\footnotetext{
*Autor para correspondência

${ }^{1}$ Recebido para publicação em 19/11/2010; aprovado em 23/02/2012

Pesquisa financiada pelo BNB, parte da Dissertação de Mestrado do primeiro autor, apresentada ao Programa de Pós-Graduação em Agronomia/Solos e Nutrição de Plantas/CCA/UFC

${ }^{2}$ Departamento de Ciência do Solo/CCA/UFC, BR 402, Bairro Rodoviária, 2472, Parnaíba - PI, Brasil, 64.210-260, deusianebs@yahoo.com.br

${ }^{3}$ Departamento de Ciência do Solo/CCA/UFC, Av. Mister Hull, 2977, Campus do Pici, Fortaleza-CE, Brasil, 60.440-554, mendes@ufc.br, vaniafreire@ufc.br

${ }^{4}$ Pós-Graduação em Agronomia/Solos e nutrição de plantas/CCA/UFC, Av. Mister Hull, 2977, Campus do Pici, Fortaleza-CE, Brasil, 60.440-554, ald_mendes@hotmail.com

${ }_{5}^{5}$ Departamento de Ciência do Solo/UFC, Av. Mister Hull, 2977, Campus do Pici, Fortaleza-CE, Brasil, 60.440-554, valderez@ufc.br
} 


\section{INTRODUÇÃO}

A bananeira é uma espécie frutífera bem adaptada às condições edafoclimáticas dos trópicos brasileiros e muito consumida em todo o País. Tais fatos fazem com que sua importância econômica na fruticultura brasileira seja superada apenas pelas frutas cítricas. O mal-do-Panamá é a doença vascular da bananeira causada pelo fungo do solo, Fusarium oxysporum f. sp. cubense (FOC), a qual compromete a produtividade da cultura, sendo caracterizada pelo amarelecimento e murcha das plantas, podendo levar à perda total da produção. O controle dessa doença é dificultado devido à grande capacidade de sobrevivência do patógeno no solo, sendo realizado, basicamente, através do uso de cultivares resistentes (CASTRO et al., 2008).

A aplicação de biofertilizantes torna as plantas mais resistentes ao ataque de pragas e patógenos, além de agir diretamente sobre os fitoparasitas devido à presença de substâncias tóxicas (DELEITO et al., 2005). Os biofertilizantes são compostos bioativos resultantes da fermentação de compostos orgânicos, que contêm células vivas ou latentes de microrganismos e seus metabólitos, além de quelatos organominerais (ALVES et al., 2001).

$\mathrm{O}$ entendimento das propriedades antimicrobianas e/ou elicitoras dos compostos secundários presentes nos biofertilizantes pode contribuir para a adoção de novas práticas de controle de pragas e doenças de plantas (BARBOSA; MEDEIROS, 2007). Além disso, a substituição total ou parcial de fertilizantes minerais e agrotóxicos por biofertilizantes tem contribuído para o aumento da produtividade das culturas (DIAS et al., 2003).

Os fungos micorrízicos arbusculares (FMA) estão presentes na maioria das plantas vasculares, sendo a ausência da associação simbiótica restrita a poucas famílias, gêneros ou espécies vegetais. $\mathrm{O}$ fungo coloniza as células do córtex da raiz hospedeira e apresenta a formação de estruturas denominadas arbúsculos e vesículas (MOREIRA; SIQUEIRA, 2006).

A ocorrência de alterações metabólicas como maior atividade fotossintética, maior atividade enzimática e de produção de substâncias reguladoras de crescimento são os principais benefícios dessa relação simbiótica para as plantas. Essas alterações conferem às plantas maior resistência aos efeitos provocados por estresses como pragas e doenças, déficits hídricos e nutricionais, ou estresses térmicos (COLOZZI FILHO; NOGUEIRA, 2007).

Segundo Barbosa e Medeiros (2007), os fungos micorrízicos arbusculares são uma das causas prováveis de resistências das plantas tratadas com biofertilizantes às pragas e fitopatógenos. Para Fortin et al. (2002), a compreensão da relação entre fungos micorrízicos arbusculares, outros componentes da biomassa microbiana do solo e as plantas é, portanto, um pré-requisito importante para a sustentabilidade.

Alguns trabalhos têm indicado que a associação simbiótica dos FMA com as plantas tem efeito benéfico na redução de sintomas de doenças em plantas cultivadas (BORGES et al., 2007; KASIAMDARI et al., 2002; TALAVERA; ITOU; MIZUKUBO, 2001; YAO; TWEDDELI; DESILETS, 2002).

Diante disso, objetivou-se avaliar o efeito da colonização micorrízica arbuscular na tolerância da bananamaçã, ao mal-do-Panamá, sob diferentes concentrações de biofertilizante e solução nutritiva, em casa de vegetação.

\section{MATERIAL E MÉTODOS}

O experimento foi instalado em casa de vegetação e o solo utilizado foi um Neossolo Quartzarênico, coletado em uma área de vegetação nativa, em um dos lotes do Distrito de Irrigação Tabuleiro de Russas. O solo foi amostrado na profundidade de $0-20 \mathrm{~cm}$, peneirado em malha de $2 \mathrm{~mm}$ e, em seguida, retirou-se uma amostra para análise química (Tabela 1). Também foi realizada uma extração de esporos do solo, por peneiramento úmido, conforme Gerdemann e Nicolson (1963), para avaliação das populações nativas de FMA quanto à diversidade e densidade. As mudas de banana-maçã (Musa spp.) foram obtidas no Laboratório de Cultura de Tecidos do Departamento de Fitotecnia, da Universidade Federal do Ceará, mediante micropropagação em meio de cultura. As mudas foram plantadas em sacos de polietileno com capacidade para $5 \mathrm{~kg}$ de substrato (solo) e cada parcela foi constituída de uma planta.

O experimento foi conduzido por um período de 140 dias. Os tratamentos foram dispostos em um delineamento inteiramente casualizado com 3 repetições e esquema fatorial 2 x 4 referente a duas densidades de esporos de FMA nativo (D1 e D2) e 4 diferentes concentrações de

Tabela 1 - Resumo das propriedades químicas do solo utilizado no experimento

\begin{tabular}{ccccccccc}
\hline Camada & $\mathrm{pH}$ & $\mathrm{P}$ & $\mathrm{K}$ & $\mathrm{Ca}$ & $\mathrm{Mg}$ & $\mathrm{Na}$ & $\mathrm{H}+\mathrm{Al}$ & $\mathrm{CTC}$ \\
\hline$(\mathrm{cm})$ & $\left(\mathrm{H}_{2} \mathrm{O}\right)$ & $\left(\mathrm{mg} \mathrm{kg}^{-1}\right)$ & & $\left(\mathrm{cmol} \mathrm{kg}^{-1}\right)$ & & \\
$0-20$ & 5,0 & 4,0 & 0,1 & 1,0 & 0,7 & 0,01 & 4,12 & 5,93 \\
\hline
\end{tabular}


fontes de nutrientes - três de solução nutritiva de Hoagland e Arnon (1950) - 40; 70 e 100\% da força iônica (Tabela 2) e uma de biofertilizante $100 \%$ (B4).

Com relação às duas densidades de esporos de FMA, D1 corresponde à densidade do solo natural (3.500 esporos $\mathrm{kg}^{-1}$ de solo) e D2 corresponde ao dobro da densidade de esporos do solo natural (7.000 esporos $\mathrm{kg}^{-1}$ de solo) adquirida pela adição de uma suspensão de esporos de FMA nativos extraídos do mesmo solo utilizado no experimento (autoinoculação). Foi aplicada uma dose de $0,45 \mathrm{~L}_{\text {planta }}{ }^{-1}$ semana $^{-1}$ das fontes de nutrientes. Essa dose e a concentração $100 \%$ do biofertilizante foram as mesmas utilizadas por Saraiva (2009) que, avaliando o efeito de diferentes concentrações de biofertilizante sobre o crescimento de mudas de banana-maçã, concluiu que esta foi a concentração que promoveu maior desenvolvimento e maiores teores de macronutrientes nas plantas. $\mathrm{O}$ biofertilizante utilizado no experimento foi obtido na Fazenda FRUTACOR, na Chapada do Apodi/CE. Pela análise química (Tabela 3), o biofertilizante apresentou acidez alta $(\mathrm{pH}-2,5)$ sendo necessário fazer sua diluição em água destilada (1:100), elevando-se o $\mathrm{pH}(5,0)$ para que pudesse ser utilizado no experimento e constituir o tratamento B4.

Aos 60 dias após o plantio, adicionou-se uma suspensão de esporos de Fusarium oxysporum f.sp. cubense (FOC), com $2 \times 10^{6}$ conídios $\mathrm{mL}^{-1}$, em todos os tratamentos. $\mathrm{O}$ isolado de FOC é originário de plantas de banana-maçã cultivadas na região do Baixo Acaraú e foi obtido no Laboratório de Fitossanidade da Universidade Federal do Ceará.

A coleta foi realizada aos 140 dias após o plantio, sendo coletadas três repetições de cada tratamento, totalizando 24 plantas para as avaliações laboratoriais.

Os parâmetros avaliados foram: a) massa da matéria seca da parte aérea (MSPA); b) fósforo na parte aérea (MALAVOLTA; VITTI; OLIVEIRA, 1989); c) colonização micorrízica arbuscular (GIOVANETTI; MOSSE, 1980; PHILLIPS; HAYMAN, 1970); d) $\mathrm{pH}$ de amostras de solo em água $(1: 2,5)$ por potenciometria e, g) índice de severidade da doença (ID) que foi avaliado observando-se os sintomas através de um corte transversal no interior dos rizomas atribuindo-se notas de 0 a 5 para cada planta.

Tabela 2 - Composição da solução nutritiva de Hoagland e Arnon (1950) utilizada no experimento e a quantidade de nutrientes fornecida a cada planta durante o experimento

\begin{tabular}{|c|c|c|c|c|c|}
\hline \multirow{2}{*}{ Composto } & \multirow{2}{*}{ Sol. estoque } & \multirow{2}{*}{$\mathrm{g} \mathrm{L}^{-1}$} & SN $100 \%$ & SN 70\% & SN $40 \%$ \\
\hline & & & $\left(\mathrm{mL} \mathrm{L}^{-1}\right)$ & $\left(\mathrm{mL} \mathrm{L}^{-1}\right)$ & $\left(\mathrm{mL} \mathrm{L}^{-1}\right)$ \\
\hline $\mathrm{KNO}_{3}$ & $2 \mathrm{M}$ & 202,20 & 12 & 8,4 & 4,8 \\
\hline $\mathrm{Ca}\left(\mathrm{NO}_{3}\right)_{2} \cdot 4 \mathrm{H}_{2} \mathrm{O}$ & $2 \mathrm{M}$ & 472,32 & 8 & 5,6 & 3,2 \\
\hline $\mathrm{MgSO}_{4} .7 \mathrm{H}_{2} \mathrm{O}$ & $2 \mathrm{M}$ & 492,98 & 2 & 1,4 & 0,8 \\
\hline $\mathrm{NH}_{4} \mathrm{H}_{2} \mathrm{PO}_{4}$ & $2 \mathrm{M}$ & 230,16 & 4 & 2,8 & 1,6 \\
\hline Fe-EDTA & $40 \mathrm{mM}$ & - & 2 & 1,4 & 0,8 \\
\hline Micronutrientes & - & - & 2 & 1,4 & 0,8 \\
\hline Nutrientes & & & & g planta $^{-1}$ ) & \\
\hline Nitrogênio (N) & & & 0,403 & 0,281 & 0,161 \\
\hline Fósforo (P) & & & 0,892 & 0,623 & 0,356 \\
\hline Potássio (K) & & & 3,376 & 2,365 & 1,350 \\
\hline Cálcio (Ca) & & & 2,310 & 1,616 & 0,924 \\
\hline Magnésio (Mg) & & & 0,350 & 0,245 & 0,140 \\
\hline
\end{tabular}

Tabela 3 - Análise química do biofertilizante e da diluição utilizada no experimento

\begin{tabular}{|c|c|c|c|c|c|c|}
\hline \multirow{2}{*}{ Amostra } & \multicolumn{5}{|c|}{$\mathrm{mg} \mathrm{L}^{-1}$} & \multirow{2}{*}{$\mathrm{pH}$} \\
\hline & $\mathrm{N}$ & $\mathrm{P}$ & K & $\mathrm{Ca}$ & $\mathrm{Mg}$ & \\
\hline Sem diluição & 28 & 312,3 & 11,2 & 26 & 36,5 & 2,5 \\
\hline $100 \%$ & 14 & 3,6 & 0,2 & 2 & 1,2 & 5,0 \\
\hline
\end{tabular}


O índice de severidade da infecção (ID) por Fusarium foi calculado de acordo com a equação 1, proposta por Cirulli e Alexander (1966) citado por Borges et al. (2007):

ID $(\%)=100\left[\sum\left(\right.\right.$ nota $\mathrm{x} \mathrm{n}^{\circ}$ de mudas $) /\left(\right.$ nota máxima $\mathrm{x} \mathrm{n}^{\circ} \mathrm{de}$ repetições)]

A análise estatística foi realizada com o auxílio do programa computacional SISVAR (FERREIRA, 2007) onde os dados foram submetidos à análise de variância e as médias comparadas pelo teste de Tukey $(p \leq 0,05)$. Os dados de colonização micorrízica e índice de severidade da doença foram transformados em arcoseno da raiz da percentagem para uniformização da variância.

\section{RESULTADOS E DISCUSSÃO}

A MSPA foi influenciada apenas pelas diferentes fontes de nutrientes $(p \leq 0,01)$, não havendo interação entre os fatores (Tabela 4) com médias de 41,6 $\mathrm{g}_{\text {planta }}{ }^{-1}$ (SN100\%), 34,8 g planta-1 (SN70\%), 29,1 (SN40\%) e 9,8 g planta $^{-1}$ para o tratamento com biofertilizante (B4) que foi significativamente inferior às demais fontes de nutrientes (Figura 1).

As diferentes densidades de esporos de FMA não influenciaram o crescimento das plantas, resultado que foi observado também por outros pesquisadores (SANTOS; CAMPOS, 2008). Entretanto, Wu et al. (2005) observaram que, em plantas de milho, a aplicação do biofertilizante contendo FMA mais três espécies de bactérias promotoras do crescimento vegetal, aumentou significativamente o crescimento das plantas.

O tratamento com biofertilizante (B4) não influenciou nas propriedades químicas do solo, justificando a baixa produção de MSPA das plantas em relação às demais fontes de nutrientes (solução nutritiva), o que pode ser explicado pela deficiência nutricional do biofertilizante
Figura 1 - Matéria seca da parte aérea das plantas de bananamaçã, em função das diferentes fontes de nutriente, aos 140 dias após o plantio

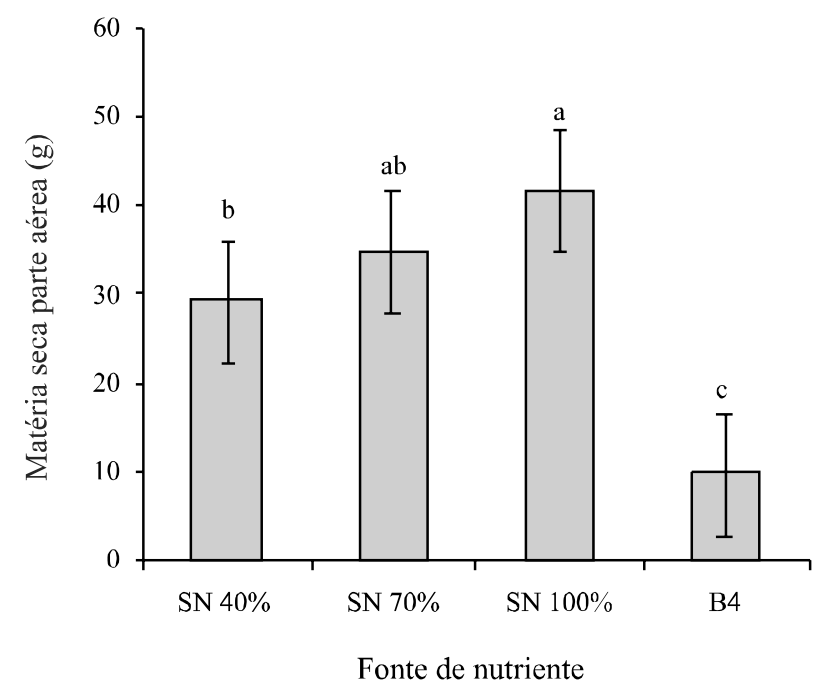

Médias seguidas da mesma letra não diferem entre si pelo teste de Tukey $(p \leq 0,05)$. SN $40 \%$ - solução nutritiva de Hoagland 40\%; SN70\% - solução nutritiva de Hoagland 70\%; SN100\% - solução nutritiva de Hoagland 100\%; B4 - biofertilizante - concentração 100\%

utilizado. As plantas responderam rapidamente à aplicação da solução nutritiva em virtude do fornecimento das quantidades de nutrientes suficientes às exigências da cultura. O teor de $\mathrm{P}$ na planta foi influenciado, significativamente, apenas pelas fontes de nutrientes $(p$ $\leq 0,01$ ) (Tabela 4). O tratamento com biofertilizante (B4) apresentou a menor concentração de $\mathrm{P}$ foliar $\left(1,85 \mathrm{~g} \mathrm{~kg}^{-1}\right)$ (Figura 2).

Na Figura 2, observa-se que as plantas tratadas com SN apresentaram maiores teores de $\mathrm{P}$ na parte aérea, por esta ser uma fonte de nutriente prontamente disponível para as plantas. Por outro lado, a quantidade de P fornecida pelo biofertilizante está muito abaixo da exigência nutricional da

Tabela 4 - Valores de probabilidade de significância dos efeitos dos fatores e suas interações sobre as variáveis estudadas, aos 140 dias após o plantio

\begin{tabular}{|c|c|c|c|c|c|}
\hline \multirow{2}{*}{ Fonte de Variação } & \multicolumn{5}{|c|}{$\operatorname{Pr}>F$} \\
\hline & MSPA $\left(\right.$ g planta $\left.^{-1}\right)$ & $\mathrm{P}\left(\mathrm{g} \mathrm{kg}^{-1}\right)$ & Colon. Mic. $(\%)$ & $\mathrm{pH}$ solo & ID $(\%)$ \\
\hline Densidade esporo (D) & $0,1530^{\mathrm{ns}}$ & $0,3590^{\mathrm{ns}}$ & $0,5268^{\mathrm{ns}}$ & $0,6714^{\mathrm{ns}}$ & $0,2929^{\text {ns }}$ \\
\hline Fonte de nutriente (FN) & $0,00001 * *$ & $0,00001 * *$ & $0,00001 * *$ & $0,0897^{\mathrm{ns}}$ & $0,0003 * *$ \\
\hline $\mathrm{D} \times \mathrm{FN}$ & $0,1132^{\text {ns }}$ & $0,2631^{\mathrm{ns}}$ & $0,8553^{\text {ns }}$ & $0,0707^{\mathrm{ns}}$ & $0,6494^{\mathrm{ns}}$ \\
\hline $\mathrm{CV}(\%)$ & 19,07 & 13,06 & 11,28 & 4,7 & 12,74 \\
\hline
\end{tabular}

$\mathrm{D}=$ Densidade de esporos de FMA; FN = Fonte de nutriente; MSPA = matéria seca da parte aérea Colon. Mic. = colonização micorrízica; ID = índice de severidade da doença; * teste $\mathrm{F}$ significativo $(\mathrm{p} \leq 0,05)$; ** teste $\mathrm{F}$ altamente significativo $(\mathrm{p} \leq 0,01)$; ns - não significativo; $\mathrm{CV}=\mathrm{Coeficiente}$ de variação 
Figura 2 - Fósforo da parte aérea das plantas de banana-maçã, em função das fontes de nutrientes aos 140 dias após o plantio

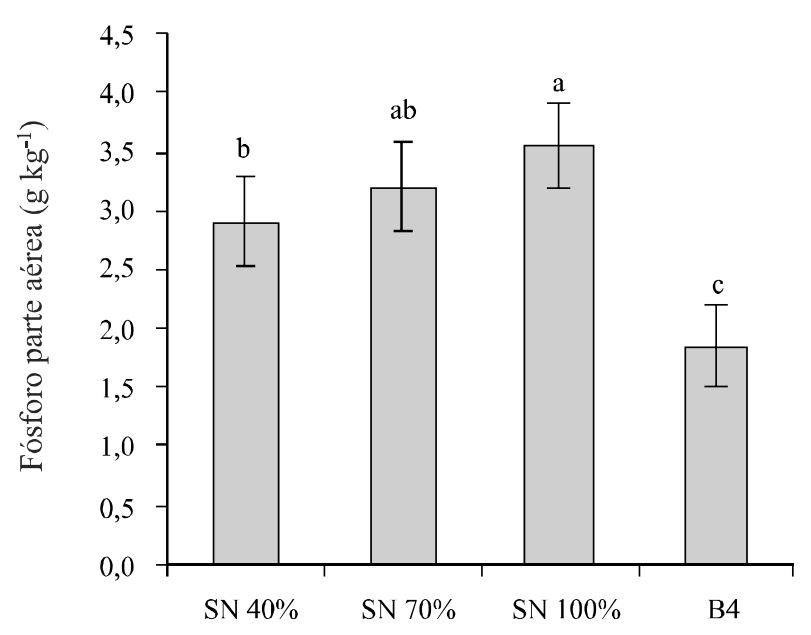

Fonte de nutriente

Médias seguidas da mesma letra não diferem entre si pelo teste de Tukey $(p \leq 0,05)$. SN40\% - solução nutritiva de Hoagland 40\%; SN70\% - solução nutritiva de Hoagland 70\%; SN100\% - solução nutritiva de Hoagland 100\%; B4 - biofertilizante - concentração 100\%

bananeira, embora, durante o experimento, os teores foliares tenham se mantido sempre dentro dos limites ideais sugeridos pela literatura (1,6-2,7 $\mathrm{g} \mathrm{kg}^{-1}$ de P) (BORGES, 2004). Dessa forma, é possível que a associação dos FMA com as raízes das plantas tenha sido efetiva para a absorção desse nutriente, uma vez que esses fungos absorvem o $\mathrm{P}$ da solução do solo e em troca as plantas disponibilizam carboidratos por ela sintetizados.

A inoculação de FMA em bananeira tem mostrado respostas positivas na absorção de $\mathrm{P}$ (TRINDADE; LINS; MAIA, 2003), mesmo sendo um macronutriente pouco absorvido pela cultura.

A colonização micorrízica não diferiu quanto às diferentes densidades de esporos de FMA (Tabela 4). Isso indica que a capacidade das plantas de bananeira de formar micorrizas não foi alterada com a quantidade de esporos no solo. O biofertilizante proporcionou a maior porcentagem de colonização micorrízica nas plantas, diferindo significativamente das demais fontes de nutrientes (Figura 3).

A aplicação de biofertilizante favoreceu a colonização micorrízica, o que não foi observado por Matos, Silva e Brasil (2002) cuja pesquisa mostrou que a porcentagem de raízes de bananeira colonizadas diminuiu no tratamento com adição de matéria orgânica, independentemente da quantidade adicionada.
Figura 3 - Colonização micorrízica nas plantas de banana-maçã, em função das fontes de nutrientes aos 140 dias após o plantio

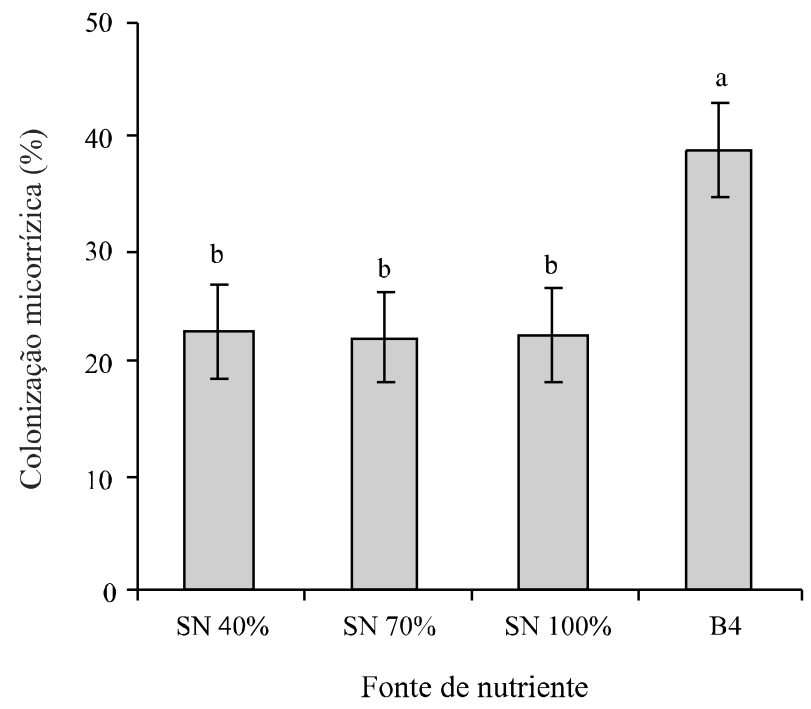

Médias seguidas da mesma letra não diferem entre si pelo teste de Tukey $(p \leq 0,05)$. SN40\% - solução nutritiva de Hoagland 40\%; SN70\% - solução nutritiva de Hoagland 70\%; SN100\% - solução nutritiva de Hoagland 100\%; B4 - biofertilizante - concentração 100\%

Observa-se que a maior disponibilidade de nutrientes proporcionada pelas três concentrações de SNs inibiu a colonização micorrízica das plantas de bananamaçã, com percentuais em torno de $20 \%$. Por outro lado, nas plantas tratadas com o biofertilizante, com quantidades muito baixas de nutrientes, a colonização radicular chegou a cerca de $40 \%$. Segundo Moreira e Siqueira (2006), esse decréscimo na colonização radicular é considerado normal, pois teores elevados de $\mathrm{P}$ inibem o estabelecimento da simbiose, com redução da intensidade da colonização. Sena et al. (2004) observaram decréscimo na colonização micorrízica com o aumento das doses de P.

A maior disponibilidade de $\mathrm{P}$ não torna as plantas imunes à colonização, apenas reduz a intensidade da micorrização. Os exsudatos de plantas deficientes em fosfato são mais estimulantes para os FMA que aqueles de plantas bem supridas em $\mathrm{P}$, indicando a presença das substâncias estimulantes nas plantas deficientes que serão mais suscetíveis à micorrização (MOREIRA; SIQUEIRA, 2006).

Resultados semelhantes foram também encontrados por Wu et al. (2005) trabalhando com milho. Nesse trabalho, o baixo nível de fertilização aumentou a colonização das raízes pelos FMA, indicando que as plantas de milho podem ser mais dependentes da simbiose micorrízica sob condições de deficiência de P.

Houve aumento não significativo do $\mathrm{pH}$ da solução do solo em todos os tratamentos, com valores entre 5,1 e 5,7, 
ficando acima do pH inicial (pH 5,0) (Figura 4). Não houve interação significativa entre os fatores de tratamento, nem efeito isolado destes sobre essa variável (Tabela 4).

Figura 4 - Variação do pH da solução do solo em função das fontes de nutrientes, aos 140 dias após o plantio.

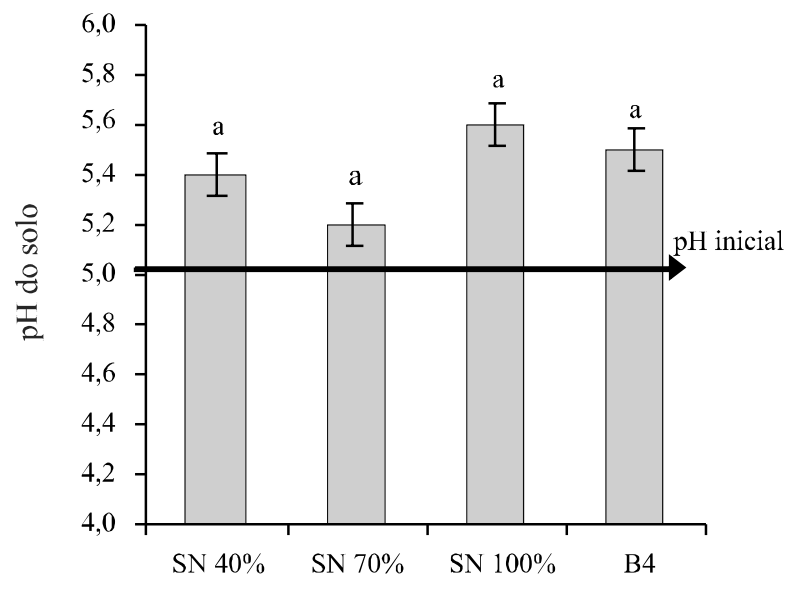

Fonte de nutriente

Médias seguidas da mesma letra não diferem entre si pelo teste de Tukey $(p \leq 0,05)$. SN40\% - solução nutritiva de Hoagland 40\%; SN70\% - solução nutritiva de Hoagland 70\%; SN100\% - solução nutritiva de Hoagland 100\%; B4 - biofertilizante - concentração 100\%

$\mathrm{O}$ pH do solo varia com a precipitação pluvial, com o manejo do solo e especialmente com as adubações, portanto é fortemente afetado pela época de amostragem do solo e, ainda, pelo método de preparo das amostras (SOUSA; MIRANDA; OLIVEIRA, 2007). Dessa forma, esse aumento do $\mathrm{pH}$ pode ter sido consequência do efeito da época explicado pela diluição causada pelo maior volume de água aplicado no solo em função do maior requerimento pelas plantas nessa fase, mudanças na composição da solução do solo em virtude da mineralização da matéria orgânica e/ou pela adubação.

As diferentes densidades de esporos de FMA no solo não influenciaram o índice de severidade da doença, sendo observada diferença significativa $(p \leq 0,01)$ apenas para o fator fonte de nutrientes (Tabela 4).

A adição do biofertilizante reduziu o índice de severidade da doença (Figura 5) em 32,2\% em relação a $\mathrm{SN} 100 \%$, que apresentou o maior índice de severidade $(48,96 \%)$. A aplicação do biofertilizante (B4) diminuiu o índice de severidade da fusariose em relação às SNs. Uma provável explicação para essa redução em B4 é a maior colonização micorrízica encontrada nas plantas desse tratamento, confirmando uma maior tolerância ao mal-do-Panamá por parte de plantas de bananeira nas
Figura 5 - Índice de severidade da doença nas plantas de banana-maçã, em função das fontes de nutrientes aos 140 dias após o plantio

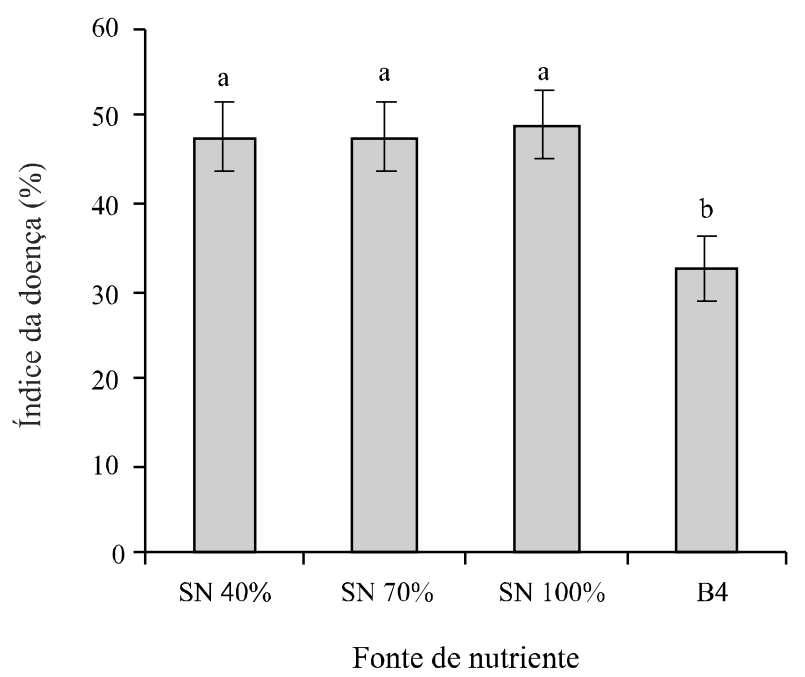

Médias seguidas da mesma letra não diferem entre si pelo teste de Tukey $(p \leq 0,05)$. SN40\% - solução nutritiva de Hoagland 40\%; SN70\% - solução nutritiva de Hoagland 70\%; SN100\% - solução nutritiva de Hoagland 100\%; B4 - biofertilizante - concentração 100\%

quais a simbiose micorrízica é mais efetiva (BORGES et al., 2007).

Para Sikes, Cotterie e Klironomos (2009), alterações morfológicas do sistema radicular das plantas provocadas pela colonização micorrízica podem diminuir os sítios de infecção para os patógenos.

Deve-se ressaltar que, segundo Moraes (2006), plantas de bananeira mostram-se severamente atacadas por Fusarium oxysporum f. sp. cubense, especialmente quando submetidas a elevadas doses de $\mathrm{P}$ aplicadas no solo, inibindo a absorção de zinco pela planta, sendo este elemento essencial na produção do ácido indol acético (AIA), que induz resistência em plantas ao incitar a produção de tiloses na parede dos vasos condutores.

$\mathrm{O}$ autor afirma ainda, que as plantas desenvolvem mecanismos de defesa como a produção de metabólitos secundários, dentre os quais os compostos fenólicos que estão mais relacionados à defesa contra fitopatógenos. A maioria desses compostos é derivada do aminoácido fenilalanina sintetizado a partir de reações catalisadas pela enzima fenilalanina amônia liase (PAL), que é estimulada por baixos níveis de nutrientes, luz e por infecções fúngicas. Também deve ser considerado que alterações na absorção de nutrientes no sistema radicular, na micorrizosfera e a ativação de mecanismos de defesa da planta podem contribuir para a inibição da doença pelos FMA (AKHTAR; SIDDIQUI, 2008; AKKOPRU; 
DEMIR, 2005). Dessa maneira, a aplicação da solução nutritiva que disponibiliza $\mathrm{P}$ para a rápida absorção pela planta, deve ter contribuído para os maiores índices de severidade da doença encontrados.

\section{CONCLUSÕES}

1. Abiofertilização das plantas debanana-maçãintensificou a colonização por fungos micorrízicos arbusculares quando comparada com solução nutritiva;

2.A utilização do biofertilizante como única fonte de nutrientes e a associação simbiótica micorrízica arbuscular diminuíram o índice de severidade da fusariose nas plantas de banana-maçã;

3. A adubação com solução nutritiva aumentou o índice de severidade da fusariose nas plantas.

\section{AGRADECIMENTOS}

Os autores agradecem ao Banco do Nordeste do Brasil pelo apoio financeiro dado a essa pesquisa e ao $\mathrm{CNPq}$ pela bolsa de mestrado do primeiro autor.

\section{REFERÊNCIAS}

AKHTAR, M. S.; SIDDIQUI, Z. A. Glomus intraradices, Pseudomonas alcaligenes, and Bacillus pumilus: efective agents for the control of root-rot disease complex of chickpea (Cicer arietinum L.). Journal General Plant Pathology, v. 74, n. 01, p. 53-60, 2008.

AKKOPRU, A.; DEMIR, S. Biological control of Fusarium wilt in tomato caused by Fusarium oxysporum f. sp. lycopersici by AMF Glomus intraradices and some rhizobacteria. Journal of Phytopathology, v. 153, n. 09, p. 544-550, 2005.

ALVES, S. B. et al. Trofobiose e Microrganismos na Proteção de Plantas: biofertilizantes e entomopatógenos na citricultura orgânica. Biotecnologia Ciência \& Desenvolvimento, n. 21, p. 16-21, 2001.

BARbosA, A. S.; MEdeIROS, M. B. Potencial de ação elicitora dos biofertilizantes líquidos na indução de resistência sistêmica vegetal. Revista Brasileira de Agroecologia, v. 02 n. 02, p. 1453-1457, 2007.

BORGES, A. L. Calagem e adubação. In: BORGES, A. L.; SOUZA, L. S. (Ed.). O cultivo da bananeira. Cruz das Almas: Embrapa Mandioca e Fruticultura, 2004. 279 p.

BORGES, A. J. S. et al. Redução do mal-do-Panamá em bananeiramaçã por inoculação de fungo micorrízico arbuscular. Pesquisa Agropecuária Brasileira, v. 42, n. 01, p. 35-41, 2007.

CASTRO, N. R. et al. Ocorrência, métodos de inoculação e agressividade de Fusarium oxysporum f. sp. cubense em Heliconia spp. Summa Phytopathologica, v. 34, n. 02, p. 127-130, 2008.
COLOZZI FILHO, A.; NOGUEIRA, M. A. Micorrizas arbusculares em plantas tropicais: café, mandioca e canade-açúcar. In: SILVEIRA, A. P. D.; FREITAS, S. S. (Ed.). Microbiota do solo e qualidade ambiental. Campinas: Instituto Agronômico, 2007. 312 p.

DELEITO, C. S. R. et al. Ação do biofertilizante Agrobio sobre a mancha-bacteriana e desenvolvimento de mudas de pimentão. Horticultura Brasileira, v. 23, n. 01, p. 117-122, 2005.

DIAS, P. F. et al. Efeito do biofertilizante líquido na produtividade e qualidade da Alfafa (Medicago sativa L.), no município de Seropédica-RJ. Agronomia, v. 37, n. 01, p. 16 - 22, 2003.

FERREIRA, D. F. Sistema de análises de variância para dados balanceados - SISVAR: programa de análises estatísticas e planejamento de experimentos, versão 5.1. Lavras: DEX/UFLA, 2007.

FORTIN, J. A. et al. Arbuscular mycorrhiza on root-organ cultures. Canadian Journal Botany, v. 80, p. 1-20, 2002.

GERDEMANN, J. W.; NICHOLSON, T. H. Spores of mycorrhizal Endogone extracted from soil by wetsieving and decanting. Transactions of the British Mycological Society, v. 46, n. 02 , p. 235-244, 1963.

GIOVANNETTI, M.; MOSSE, B. Na evaluation of techniques for measuring vesicular arbuscular mycorrhizal infection in roots. New Phytologist, v. 84, p. 489-500. 1980.

HOAGLAND, D. R.; ARNON, D. I. The water culture method of growing plants without soil. Berkeley: University of California, 1950. $32 \mathrm{p}$.

KASIAMDARI, R. S. et al. Influence of the mycorrhizal fungus, Glomus coronatum, and soil phosphorus on infection and disease caused by binucleate Rhizoctonia and Rhizoctonia solani on mung bean (Vigna radiata). Plant and Soil, v. 238, n. 02, p. 235-244, 2002.

MALAVOLTA, E.; VITTI, G. C.; OLIVEIRA, S. A. Avaliação do estado nutricional de plantas: princípios e aplicações. Piracicaba: Associação Brasileira para Pesquisa da Potassa e do Fosfato, 1989. $201 \mathrm{p}$.

MATOS, R. M. B.; SILVA, E. M. R.; BRASIL, F. C. Micorriza arbuscular e matéria orgânica na aclimatização de mudas de bananeira, cultivar Nanicão. Bragantia, v. 61, n. 03, p. 277-283, 2002.

MORAES, W. S. Nutrição mineral e sanidade da cultura da bananeira. Informações agronômicas, n. 116, p. 15-17, 2006.

MOREIRA, F. M. S.; SIQUEIRA, J. O. Microbiologia e Bioquímica do Solo. 2. ed. Lavras: UFLA, 2006. 729 p.

PHILLIPS, J. M.; HAYMAN, D. S. Improved procedures for clearing roots and staining parasitic and vesicular-arbuscular mycorrhizal fungi for rapid assessment of infection. Transactions of the British Mycological Society, v. 55, n. 01, p. 158-161, 1970.

SANTOS, A. A.; CAMPOS, O. R. Efeito da aplicação de micorrizas no crescimento de tomate estaqueado em casa de vegetação no município de Alta Floresta - MT. In: FERTBIO 2008, Londrina. Anais... Londrina: Embrapa Soja: SBCS: IAPAR: UEL, 2008. 1 CD-ROM. 
SARAIVA, J. P. B. Atividade da microbiota do solo e desenvolvimento de mudas de bananeira biofertirrigadas. 2009. 81 f. Dissertação (Mestrado em Agronomia). Universidade Federal do Ceará, Fortaleza, 2009.

SENA, J. O. A.; LABATE, C. A.; CARDOSO, E. J. B. N. Caracterização fisiológica da redução de crescimento de mudas de citros micorrizadas em altas doses de fósforo. Revista Brasileira de Ciência do Solo, v. 28, n. 05, p. 827-832, 2004.

SIKES, B. A.; COTTENIE, K.; KLIRONOMOS, J. N. Plant and fungal identity determines pathogen protection of plant roots by arbuscular mycorrhizas. Journal of Ecology, v. 97, n. 06, p. 1274-1280, 2009.

SOUSA, D. M. G.; MIRANDA, L. N.; OLIVEIRA, S. A. Acidez do solo e sua correção. In: NOVAIS, R. F. et al. (Ed.). Fertilidade do Solo. Viçosa: SBCS, 2007. 1017 p.
TALAVERA, M.; ITOU, K.; MIZUKUBO, T. Reduction of nematode damage by root colonization with arbuscular mycorrhiza (Glomus spp.) in tomato-Meloidogyne incognita (Tylenchida: Meloidogynidae) and carrot-Pratylenchus penetrans (Tylenchida: Pratylenchidae) pathosystems. Applied Entomology and Zoology, v. 36, n. 03, p. 387-392, 2001.

TRINDADE, A. V.; LINS, G. M. L.; MAIA, I. C. S. Substratos e fungo micorrízico arbuscular em mudas micropropagadas de bananeira na fase de aclimatação. Revista Brasileira de Fruticultura, v. 25, n. 01, p. 137-142, 2003.

WU, S. C. et al. Effects of biofertilizer containing N-fixer, $\mathrm{P}$ and $\mathrm{K}$ solubilizers and AM fungi on maize growth: a greenhouse trial. Geoderma, v. 125, n. 01/02, p.155-166, 2005.

YAO, M. K.; TWEDDELL, R. J.; DÉSILETS, H. Effect of two vesicular-arbuscular mycorrhizal fungi on the growth of micropropagated potato plantlets and on the extent of disease caused by Rhizoctonia solani. Mycorrhiza, v. 12, n. 05, p. 235-242, 2002. 